\title{
Who wants to be able to do references properly and be unemployed? STEM student writing and employer needs
}

\author{
Yvon Appleby \\ University of Central Lancashire, UK \\ Sian Roberts \\ University of Central Lancashire, UK \\ Lynne Barnes \\ University of Central Lancashire, UK \\ Pam Qualter \\ University of Central Lancashire, UK \\ Vicki Tariq \\ University of Central Lancashire, UK
}

\begin{abstract}
The issue of graduate writing is one that has attracted much focus and debate in higher education, particularly around maintaining 'academic standards' at a time of expansion in this sector. The need to develop academic skills, including writing, for higher education study has increasingly been linked to the skills that graduates need to gain employment (Davies et al., 2006). This raises the question of whether the type and purpose of writing within university programmes is different to, and possibly in tension with, writing required for employment after university. This is a point raised by recent research (Day, 2011) which shows that students studying STEM (Science, Technology, Engineering, and Maths) subjects are more confident with oral rather than writing skills. The material discussed in this article is part of a two-year mixed method study looking at literacies, including writing, which undergraduate students develop at university, and the relationship of these literacies to employability. This article focuses on six first-year STEM students studying Forensic Science and Computing Science within the larger study. The qualitative data, gathered through repeat interviews, is discussed in relation to a small sample of employers and alumni working in science-based industries describing writing for transition into work and for on-going employment. The project therefore provides a useful
\end{abstract}


student insight into writing, comparing this with employer expectations and the experience of alumni who have made the transition into work. What emerges from our study is the need to see writing at university as part of a wider communicative repertoire supported by a social and cultural approach to situated writing. This approach is more than simply skills based and is one that encourages and develops social as well as academic learning. We argue that such an approach, added to by technical skills support, enables greater engagement and success with learning in addition to enhancing employability.

Keywords: student writing; STEM subjects; employability; social practices; literacies.

\section{Introduction}

The standard of undergraduate writing has caused widespread concern across the higher education sector, with some authors reporting it being regarded by the media as a 'literary crisis' in the UK (Ganobcsik-Williams, 2004, p.5). Others working in the field of student or academic writing describe the shortcomings of students' writing as impacting directly upon the ability to learn, where inadequate writing skills act to 'disable' students (Davies, et al., 2006). The significance of writing as an academic vehicle to communicate, express and explicate ideas is described by Kotzee and Johnson (2008) as a 'threshold skill'; for them a skill central to the intellectual development and core identity of being a student. Writing is a central activity whilst at university, and in other institutions offering higher education, as it is often core to teaching and assessment in most subjects. It is what students do, it is what is required of them, and is therefore an integral part of how students make sense of the world of university and higher education. As such it is a significant part of the material embodiment of the student identity, where individuals develop a sense of 'being' (Clughen and Hardy, 2012) within the identity process of 'becoming' (Gourlay, 2009) a university student.

Pedagogical responses to general concerns about what is seen as a decline in undergraduate writing standards have varied. Some, for example, focus on working with curricula and technical workshops to support and embed writing skills at an institutional level using academic writing templates (Fallows and Steven, 2000; Cox and King, 2006). For others, the focus is in recognising the significance of external partnerships and experiential and social learning, rather than a focus on technical skill, as part of academic 
writing development (Leckey and McGuigan, 1997; Davies, 2000). These examples illustrate different responses: in the first the emphasis is on technical ability or competence in academic writing within university programmes; the second is on purpose and meaning of situated writing tasks. A distinction is apparent, here and in the literature, between a focus on technical remedial solutions, in the first, as opposed to engaging with wider social and cultural purpose and meaning in the second.

Whilst there are general concerns with the standard of undergraduate writing there are also specific issues within particular disciplines or areas of study. For example, in a study of Accounting and Engineering students it was found that employers demand high levels of communication skills with the expectation that university should teach these skills. However, it was found that there were significant differences between Accounting and Engineering students as the latter displayed writing apprehension in written reports; their main method of written communication. The outcome of this insight was not to focus on generic communication skills, which some universities have done, but to concentrate on focused writing skills for specific areas of study and future employment (Hassall et al., 2005). Others have developed discipline-specific student writing programmes in, for example, Psychology (Fallahi et al., 2006), Information Technology (Armarego, 2008) and Radiography (Gonzaga et al., 2011).

A specific subject area was also the focus of recent research, part of the Higher Education Curriculum project 'Developing Writing in STEM disciplines' (Day, 2011). This project studied the requirements, concerns and expectations of engineering employers with regard to student placements and graduate employees. The research found a general agreement by employers and university staff that the university should support placement students, including in a range of written tasks perceived to be different to academic skills but those required of graduate employees in the workplace. Findings from the project showed that faculty staff, students and industrial supervisors in the study tended towards an instrumental view of writing development. This was apparent in a more competencybased approach to the skills needed to successfully complete a task or operation in the work environment. This instrumental approach has a different emphasis to the critical and analytical skills required by the undergraduates at university requiring metacognition and independent thinking. These different approaches were experienced as particularly difficult where students crossed from academic writing at university to industrial writing in their placement, and then back to academic writing at university. Recommendations from the 
project include, amongst others, reinforcing the benefits of strong communication skills for employability to students, mapping activities between university study and employment, and extending the repertoire of students' writing to bridge the gaps between university and placement using development frameworks such as IPACE (identity, purpose, audience, code and experience). Our research project, discussed next, also focused on aspects of written communication developed by first-year university students and explored how their skills and knowledge related to what was required by employers.

\section{The study}

The two-year mixed method study, funded by the Higher Education Academy, called 'Literacies Supporting Learning and Enhancing Employability in a Diverse Undergraduate Population' was based at the University of Central Lancashire, a large post-1992 university in the North West of England (the term 'post-1992 university' describes higher education institutions, often Polytechnics, that were given university status including degreeawarding powers in 1992). The multidisciplinary study focused on communication literacy, mathematical literacy, information literacy and emotional literacy, and generated data from four Schools within the university. These Schools represented a range of STEM and humanities subjects including Psychology, Forensic Science, Computing Science, Education and History. The four Schools were targeted specifically to provide a range of experiences and views of science and humanities undergraduates, employers and alumni. First- year entrants in these Schools were approached directly by the research team, who attended lectures and seminars to explain about the project, with accompanying information sheets, and asked for volunteers to take part in the study. The quantitative data for the study was gathered using phased online survey questions, in addition to literacy and mathematics tests, with the 116 first-year students who responded to our request. The employers, likely to recruit graduates from these Schools, were contacted with a request for volunteers through university networks, employer forums and personal contact with 50 employers taking part in the project's online employer survey. Past graduates were contacted through the university Alumni Office, by targeting graduates from the four Schools who had graduated in the last four years and who had found graduate-level employment, often in their fields of study. From those contacted, 60 individuals completed the project's online alumni survey. 
Students who completed the surveys and tests were invited to participate in two follow-up interviews in order for the research team to gain more detailed qualitative information about these students' adjustments to university and their uses and development of information literacy, mathematical literacy and communication literacies at university. Communication literacy included both writing and oral skills and practices. Twenty students who volunteered were invited for interview twice, once at the beginning of their first year, representing their transition into HE, and again at the end of the first year when they reflected on progress and the future. The in-depth, semi-structured interviews were recorded and transcribed. As part of the qualitative data set we also interviewed nine employers and nine alumni who had taken part respectively in the online employer and alumni surveys. In these recorded telephone interviews we focused on the literacies within our study that were needed for employment. Additionally we asked both employers and alumni if they thought that students leaving university had the necessary understanding and skills, including writing, for graduate employment.

The data used for this article are derived from interviews with six students from Forensic Science and from Computing Science, as they most closely match the STEM subject areas. As a small self-selected sample they are not necessarily representative of all students in these subject areas or across all universities, but they do provide a valuable and often missing voice in the debates about students' writing and learning. As there is a concern that writing at university, in any subject, should not be seen purely as academic skills acquisition, we will consider this concern in light of what employers and alumni say, particularly as employers often do not appoint on subject knowledge when communication, including writing, may be considered more important than the degree subject or classification.

In the first set of interviews we asked about the students' experience of learning at A level and adjustments to coming to university to study. Although most said they had enjoyed developing knowledge of the subject, there were descriptions of being 'spoon fed' by teachers at school, college and sixth form. Several reflected that in this environment they had not learned to write for understanding; it was more to exhibit knowledge to pass exams, using what was described as a formulaic approach to writing which did not encourage independence. For example Bradley (pseudonyms are used throughout), a Forensic Science student, recalled writing in the sixth form pre-university where his teachers 'would just write out and you would copy'. Lucy, also a Forensic Science student, 
felt although she had anticipated the adjustment to a more independent way of working at university, she still struggled to keep pace with note taking and reading. She felt unprepared and that high school should be, in her words, less 'caring and patting you along'. Computer Science student Daniel also felt unprepared in dealing with referencing and plagiarism at the beginning of his course: 'They are very strict about plagiarism which is something I wasn't expecting. It is difficult the academic writing'. He felt this emphasis was often in tension with his technical and subject knowledge as an advanced computer user, creating frustration and lower marks on his assignments.

The students' reflection about their writing skills, in their first interview and at the point of transition into higher education study, echoes findings from a previous study researching students' expectations on entering higher education (Cook and Leckey, 1999). Cook and Leckey's study found that many entrants had previously not taken responsibility for their own learning as parents and school had provided both support and external motivation. They suggest that teaching and assessment styles in many schools lend themselves to developing study skills that may be appropriate at that level but are not appropriate for higher education. They conclude that many students are therefore unrealistic in what they expect university to be in terms of class size, degree of independence and time required to study. Although Cook and Leckey's study is somewhat dated, this point is also made in recent writing by Clughen and Hardy (2011) suggesting it is a persistent problem.

In a similar way to the students in Cook and Leckey's (1999) study, part of this transition concerned developing more independent study skills where the students valued critical tutor feedback to help them develop written work. The comments from our interviewees above suggest that they are reviewing their study skills, assessing what is positive and less so, as part of their move towards independent learning. Junaid, a Computing Science student, particularly valued written assignments such as reports and essays as he felt that he could receive more detailed feedback. This was also mentioned by Lucy who used writing assignments to test her own level of skill and knowledge. Whilst she was confident in giving presentations using Powerpoint, she explained that she 'just wanted to test the essay more and make sure I was getting all that right and the references'. Three of the six students also reported similar views of essays and written assignments which provided formal structure for feedback, clearly identifying areas for improvement and development. In the three interviews, although described in slightly different ways, the students felt they were able to distinguish between feedback comments about content, including the need 
for additional information, and academic writing skills including structure, spelling and references. This layer of individual support for academic development the six students described was provided by their module tutors, who were regarded variously as 'brilliant' and 'open and willing to communicate'. The tutors provided general information about academic writing, helping to translate what was required for specific projects and assignments, and responded with clear feedback. Where feedback was not clear the individual students felt able to contact the tutor for clarification, either through e-mail or catching him or her after a lecture or seminar. The feedback process was described as more interactive and mutually responsible in contrast to their previous learning experiences. This was an aspect of higher education learning also highly valued by students in Cook and Leckey's (1999) study of first-year students' expectation of university.

In a similar way to the various approaches to support student writing mentioned above, including both technical skills-based and social, cultural and situated approaches (Fallows and Steven, 2000; Cox and King, 2006; Davies, 2000), the university where the study was carried out offers various kinds of support which the students we interviewed used to help develop their writing skills. Peter used WISER (advertised as 'don't be none the wiser') the university academic writing support team. For most students this is an additional and individual service to support writing development in specific areas. Peter explained that he used it to learn about referencing, which he described as 'an alien concept' not having covered it at A level. Even those who had not used these services were aware of their existence and felt secure that they could receive additional writing support if needed.

In addition to these more formal mechanisms, an interesting finding emerged from our interview data which showed that a great deal of informal learning and peer support was occurring, especially for the Computer Science students. These fellow computing students were in Ben's words 'geeks' who he felt often liked to work on their own. Such informal and collaborative learning was in contrast to what had been described by some as a mainly teacher-pupil focused experience before university. Activities which showed adjustments in study techniques in this transition period included online support, individual coaching sessions, extended collaboration of ideas and editing. Peter, studying Computer Science, described his informal writing network: 
Everyone's got a good work ethic and they all start their essays early...We spend all day together, we'll be chatting for particular assignments on how we approached it, we'll even share notes...it's been fantastic for all of us working at this level, we've just collected the best of our knowledge and applied it to the things we have done.

Ben provided another example, explaining that he would see if someone had a problem even if he did not need help himself. Whilst Bradley, studying Forensic Science, described his informal writing support network:

I've shown [my assignment] to a couple of people on my course, like a kind of peer review thing and they were fine...I mean we all tend to proof read and stuff for each other...it's like 'I'm not sure how to do this' so pop around and show someone, it's informal.

Lucy, studying Forensic Science, developed a more one-to-one coaching arrangement in Chemistry with another student who lived at some distance from the university: '[It is great] she will just stay that extra hour just to explain something to me which is excellent'.

If learning academic writing is part of the transition and a sign of success at university, what of writing skills needed at the point of exit and transition into employment? To explore the relationship of academic writing skills developed by undergraduates to those required for graduate employment we interviewed a small number of employers and alumni. We interviewed nine employers who between them covered a range of employment sectors and sizes; from a large city Law firm, a Scottish Risk Management firm, to a multinational technical manufacturing firm. There were several significant threads that emerged across the employer interviews which can be summarised as: the high value placed upon work experience (both general and through placements); the subject area of the degree was not the most significant factor for employability; good communication and team work skills were highly valued; a strong work ethic with the ability to work independently and responsibly was valued; and lastly, for most although not all, there was a concern with falling standards of writing. The two employers who recruited STEM graduates in our study were a multinational technical manufacturing company and a medium-sized materials technology manufacturing firm in the North West of England. We focus on their interviews in this article. Harold was technical recruitment and training manager in the multinational firm and Richard was head of materials in the medium-sized technology firm. 
Richard described looking for what he termed 'raw material' when recruiting and employing graduates. He explained this was because employees needed a broad-based technical degree but also needed to be able to operate in what he called a commercial 'hard-nosed' environment something he felt was different to an academic institution. He described looking for candidates who used their initiative, often to get relevant work experience in, for example, a lab. A similar approach, looking for broad rather than tightly-defined, subjectbased experience or qualifications, was echoed by Harold. In his role as graduate recruitment and training manager he accepted graduates in related subjects like mechanical engineering but prioritised practical and manufacturing experience. He described wanting people with relevant understanding from the shop floor or engineering works. Harold contrasted the pressure of working in industry with that of academic work, where students had, in his opinion, little sense of the reality of deadlines, what he described as the luxury of 'weeks and weeks to complete a dissertation'. Both employers pointed to wanting people with life skills and life experience. Richard described this as looking for maturity in a graduate applicant; someone, in his words, who was sensible, enthusiastic and right for the environment. Harold said he looked for self-confidence and the ability to make decisions - he contrasted this with a recent well-qualified applicant from a prestigious university whom, he felt, was 'almost too intelligent for his own good really'.

When asked about the writing practices within their working environment there was greater contrast between the two employers. Richard explained that in his work environment $90 \%$ of communication was by e-mail and texting using smart phones which he described resulted in 'shorter, sharper, communication...virtually no letter writing goes on anymore'. He accepted that many of the graduates whom he interviewed and recruited did not have good levels of writing; however, for his work this was less important than working quickly and flexibly in a team using multimodal and digital methods of communication. On the other hand, Harold, although agreeing that numeracy was more significant for his work environment, was disappointed by what he saw as a decline of graduate writing standards. He commented that '... if they can't be bothered to spell check something, that is disappointing'. He explained that the recruitment process had been adapted to respond to this decline in standards, and whereas previously his company had only allowed four spelling mistakes in the job application it had meant they were refusing so many applicants that the acceptable number of spelling errors had been raised to ten. 
When they were asked as employers what university could do to prepare graduates for work and develop the skills they needed, both Richard and Harold felt that students should know about the 'real' world of work. Richard described how he felt university was different to work in standards of discipline or punctuality, commenting that 'I think preparing them for the real world of work is not particularly high on either school or universities' agenda'. Harold described a lack of understanding of the real world and looked for candidates who demonstrated what he called 'a bit of get up and go' rather than what he described as 'being expected to be led everywhere'. He also felt that graduates misunderstood the relevance of their degree to their employability:

They probably need to appreciate that educationally they are in excess of what we need. Yes we need them to have an engineering-related degree but they probably won't use $90 \%$ of that degree. But what we are looking for is that they can grasp things quickly and make a decision and stick to it and see it through to completion...they might be ok on the technical side but in terms of the practical side, some of them have never been to a factory before.

Richard and Harold, as STEM subject employers, are echoing what other employer studies have found: that subject knowledge, specific technical skills or university ranking are not the primary factors for selection and employment. In a survey of 100 employers in East Anglia, Hinchcliffe and Jolly (2011) asked participants to rank employability skills in order of importance for recruiting graduate employees. Out of a possible seven categories, interpersonal skills was seen as most important, with written communication seen as number three and Information Technology fourth. This is similar to findings from previous studies (Morley, 2007) that found across eight categories, interpersonal/team skills were the most highly rated, with what were referred to as core skills, for example communication (which included writing), being rated third. Interestingly degree classification and subject knowledge were rated much lower, at sixth place.

Morley's (2007) and Hinchcliffe and Jolly's (2011) findings endorse what an alumni Forensic Science graduate, now working as a lab technologist, told us in her interview. She reported that she got the job in the aerospace industry, not in her area of expertise or graduate knowledge, as her employer 'knew he could trust me...it doesn't matter what your degree is in, what matters is the skills you learn'. This graduate had worked for this company on several short-term contracts and maternity cover in chemical analysis, in areas not specifically related to her graduate subject. She felt that she had gained her 
permanent job with this firm by showing her capacity to learn new skills and to be able to apply general critical and analytical skills learned at university within the work environment.

\section{Discussion}

Our findings suggest that STEM employers in the study are looking for graduates with broad communication skills, including writing, but more importantly are looking for qualities such as maturity, the ability to work with others and to work with complex problems within their specific work environments. These findings raise questions of how skills required in the workplace relate to academic writing required at university. The findings show the importance of aligning two strands of discussion about student writing mentioned in this article, where technical skills-based learning can underpin a social and cultural approach to situated writing. A technical skills-based approach to student writing may improve competency but does not on its own provide sufficient understanding of how writing may be used and developed within new contexts. If writing skills are not accompanied by understanding at a metacognitive level of purpose, audience and situation, they may remain significant for academic purpose only. The potentially academically bounded nature of some of the writing development at university was a concern expressed, albeit differently, by both students and employers. The employers in our study wanted graduates that could adapt existing writing and communication skills as well as develop new ones that fitted the working environment. The students wanted to develop writing and communication skills to enable them to gain a degree, but they wanted more than proficiency in tasks such as being able to reference appropriately. They expressed a need to achieve understanding which was transportable and could be applied to work. In both cases writing and communication was expressed as more than a technical skill. Although acquiring greater writing and communication competence was seen as an important learning development at university, understanding and developing writing as social, cultural and situated practice was also significant.

The debate between technical skills-based and social practice approaches has been significant in discussion of student writing in higher and further education. Ursula Wingate (2006) argues that in the UK, the notion of writing as a skill prevails where any problem is recognised as textual, with technical solutions leading to an improvement of skill. She observes that skills such as referencing are taught but the more difficult aspects of 
understanding sources and how knowledge is constructed and debated are not. Therefore students, especially those in technical subjects, may be encouraged to view academic writing as instrumental and based on technical competency. Wingate, in a later publication (2007), suggests that what is required is an epistemological shift, as understanding the conception of knowledge in one's discipline is a fundamental aspect of effective learning in higher education. As part of this shift, away from a simple skill view of writing, students also need to understand their role as learners in higher education, becoming independent learners who understand knowledge and are competent in constructing knowledge in a discipline. A technical or instrumental skills approach, concentrating on the 'how to' of writing fails to address the more important critical and metacognitive 'what' of the content and meaning that is being communicated.

The connection of learning, knowledge construction and critical thinking as a basis for developing undergraduate writing appears to relate to what Kotzee and Johnson (2008) refer to as a 'threshold concept'. Work by Meyer and Land (2003), and subsequently developed (Land et al., 2005; Davies and Mangan, 2006), explains threshold concepts as the key concepts and knowledge students need to 'master' their subject. What is difficult to see is how the notion of threshold concepts, applied to university study, relates to employability and the qualities employers expect from graduates suggested in previous research (Morley et al., 2006; Hinchcliffe and Jolly, 2011) and in our data. Mastery of the particular subject through higher education study appears at odds with the more general personal experience and attributes, such as work ethic and maturity, required by STEM and other employers. If, however, we include the concept of learning itself, it is possible to see how undergraduate skills, including writing, can be used and developed in higher education and in the workplace.

The Dearing report (Dearing, 1997) was significant in defining key skills for employment, emphasising the notion of employability within education across all sectors including school, further and higher education, and Lifelong Learning. The key skills in the report were defined as communication (including oral and written), numeracy, IT and 'learning how to learn'. Many working in higher education have been critical of a simple skills approach designed to support graduate employability (for example, Knight and Yorke, 2004). What is less mentioned but is significant within this debate is the fourth key skill mentioned by Dearing (1997); learning how to learn. Moving this to a more central position in the discussion encourages concentration on the processes rather than the products of 
learning. The distinction between the product and process of learning was illustrated by the students in the example of being able to cite and reference appropriately. It is possible to see that learning how to reference correctly, a difficulty expressed in the first interviews by the students themselves, relates to their previous described learning experiences of being 'spoon-fed'. The latter approach they explained didn't give them the skills or a significantly deeper understanding of what the knowledge was or how it was constructed; success was viewed as more product-based. By the second interview when the students described learning to do references, essays or reports as part of their academic writing, they were largely describing this not just as developing technical skill but as part of a wider communicative repertoire and part of understanding how they learned. In these accounts the students were describing a process of learning rather than learning that was focused primarily on a product. Some of the awareness of learning was self-generated and linked to specific tasks while much was social and informal. In constructing their academic identity through writing (Ivanic, 1998) they were engaging with many social practices: as a student, a colleague, a mentor and employee, all of which impacted upon their learning. This included formal, informal, academic and social sites of learning. The students used different sources and resources to support this learning including tutor support, specific academic writing support, immediate friends and online groups. They were learning technical aspects of writing, such as referencing, but saw this as part of their overall learning how to learn, distinctly different to their previous experiences, and not simply as an end in itself.

Acknowledging that the students were aware of, and in some cases proactive in, learning how to learn suggests the possibility of relating this understanding more closely to what employers' value in graduate employees. Employers in our study also indicated they did not want spoon-fed graduate employees. Being able to use references may not be seen by many employers as a straightforwardly useful transferable technical skill; however, understanding how to learn the new skill and the knowledge that underpins it is. Developing this new skill, particularly when underpinned by an awareness of the learning processes involved, may rely upon, and can provide evidence of, team work, independent thinking, problem solving and wider communication. The six students in various ways described working with others to plan and give presentations, supporting friends and colleagues in essay planning and in editing each other's work. Some of these writing skills supporting writing and communication proficiency, although linked to university study, 
would lead to increased chances of employment as it illustrates general skills and competencies that employers value.

It is important therefore to view writing in educational settings, at whatever age, as dynamic and potentially responsive to wider socio-cultural contexts (Fisher, 2012). A social practices approach to literacy, including reading and writing, takes account of purpose, history, culture and situation (Barton et al., 2000), enabling recognition of both motivation and learning processes. A social practice approach to learning (Lave and Wenger, 2005; Lave, 2009) also illustrates the need to distinguish between intentional instruction and learning; observing that learning is not always an outcome of instruction. Therefore writing instruction (which may be technical and skills oriented) may be less effective than developing an understanding of learning processes; an understanding which is recognised and valued by employers. Understanding the learning processes involved in writing, through collaboration, using Facebook and informal meetings was something the students drew upon themselves in developing their social and collaborative networks.

\section{Conclusion}

Rather than offer a simple solution suggesting that STEM students need more practice in report writing, or even in giving presentations, which was highly valued by our student interviewees for developing skills used at work, it is at least as important to comprehend how students learn and to support their understanding of learning processes. Interventions such as skills sessions have a part to play in that process but cannot simply be ends in themselves. Developing writing, as the students in our study showed in their independent and collaborative activities, can also take place outside of the classroom or the formal curriculum. Acknowledging social learning, inside and outside of university, begins to align developing communicative repertoires that support learning to learn as well as the group work skills and independence that employers value. This may mean changing assessment practices within university teaching to encourage or recognise this development, and to acknowledge interaction between social, emotional and cognitive dimensions in learning (Illeris, 2002). It may be through building virtual communities of practice (Hargreaves and Gibels, 2011) or by linking a workplace curriculum (Billett, 2011) to what is learned at university, recognising the significance of what Stephen Billett calls participatory practices (Billett, 2004). The above suggestions would benefit from a supportive cultures approach 
(Clughen and Hardy, 2012) that uses writing spaces to explore and develop writing as a social practice, producing writing that is individually distinct rather than simply what is required.

Learning, of course, does not stop when a student exits university. Indeed, the employers we interviewed indicated they wanted what they described as 'raw material' to work with. This was explained as a graduate with an appropriate general level of skill in the core literacies we investigated (communication literacy, mathematical literacy, information literacy and emotional literacy) but who is open to learning new skills and knowledge for the job. Understanding better the relationship between processes of learning at university and those in work may help to address student and employer fears, that academic practices such as being able to cite and reference appropriately indicate a critical understanding of knowledge construction rather than a university-bound, technical skill, which may not be valued once the student graduates. Doing so requires a focus on learning to learn rather than on students' skill acquisition or subject competency.

\section{References}

Armarego, J. (2008) Engaging IT students in enhancing writing skills. Murdoch, Australia: Murdoch University.

Barton, D., Hamilton, M. and Ivanic, R. (2000) Situated literacies. London: Routledge.

Billett, S. (2004) 'Learning through work: workplace participatory practices', in Rainbird, H., Fuller A. and Munro A. (eds.) Workplace learning in context. London: Routledge, pp. 109-126.

Billett, S. (2011) 'Workplace curriculum: practice and propositions' in Dochy, F., Gibels, D., Segers, D. and Van Den Bossche, P. (eds.) Theories of learning for the workplace. London: Routledge, pp. 17-37.

Clughen, L. and Hardy, C. (2011) 'Creating participatory writing cultures in UK higher education', Journal of Academic Writing, 1(1), pp. 71-78. 
Clughen, L. and Hardy, C. (2012) Writing in the disciplines: building supportive cultures for student writing in UK higher education. Bingley: Emerald Publishing.

Cook, A. and Leckey, J. (1999) 'Do expectations meet reality? A survey of changes in firstyear student opinion', Journal of Further and Higher Education, 23(2), pp. 157-171.

Cox, S. and King, D. (2006) 'Skills set: an approach to embed employability in course design', Education and Training, 48(4), pp. 262 -274.

Davies, L. (2000) 'Why kick the 'L' out of LEarning?' The development of students' employability skills through part-time working', Education and Training, 42(8), pp. 436-444.

Davies, P. and Mangan, J. (2006) 'Embedding threshold concepts: from theory to pedagogical principles to learning activities': Threshold Concepts within the Disciplines Symposium. University of Strathclyde, Glasgow 30 August - 1 September.

Davies, S., Swinburne, D. and Williams, G. (2006) Writing matters. London: The Royal Literary Fund.

Day, T. (2011) 'Developing writing in STEM disciplines': SW Conference for Developing Writing in STEM Disciplines. University of Bath 12 September. Available at: http://www.hestem-sw.org.uk/project?id=5\&pp=125 (Accessed: 2 November 2012).

Dearing (1997) Higher education in the learning society: the report of the National Committee of Inquiry into Higher Education. London: HMSO.

Fallahi, C., Wood, R. and Auatad, C. (2006) 'A program for improving undergraduate psychology students' basic writing skills', Teaching of Psychology, 33(3), pp. 171177.

Fallows, S. and Steven, C. (2000) 'Building employability skills into higher education curriculum: a university wide initiative', Education and Training, 42(2), pp. 75-82. 
Fisher, R. (2012) 'Teaching writing: a situated dynamic', British Educational Research Journal, 38(2), pp. 299-319.

Ganobcsik-Williams, L. (2004) A report on the teaching of academic writing in UK higher education. London: The Royal Literary Fund.

Gonzaga, M., Elsie, K. and Francis, B. (2011) 'Faculty and students' perspectives and opinions regarding the use of case reports to develop scientific writing skills among undergraduate students', South African Radiographer, 49(2), pp. 18-22.

Gourlay, L. (2009) 'Threshold practices: becoming a student through academic literacies', London Review of Education, 7(2), pp. 181-192.

Hargreaves, S. and Gibels, D. (2011) 'From the theory of situated cognition to communities of practice: J. Lave and E Wenger', in Dochy, F., Gibels, D., Segers, M. and Van Den Bossche, P. (eds.) Theories of learning for the workplace. London: Routledge, pp. 66-79.

Hassall, T., Joyce, J., Bramhall, M., Robinson, I. and Augero, J. (2005) 'The sound of silence? A comparative study of the barriers to communication skills development in accounting and engineering students', Industry and Higher Education, October 2005, pp. 392-398.

Hinchcliffe, G. and Jolly, A. (2011) 'Graduate identity and employability', British Educational Research Journal, 37(4), pp. 563-584.

Illeris, K. (2002) The three dimensions of learning. Roskilde: Roskilde University Press.

Ivanic, R. (1998) Writing and identity: the discoursal construction of identity in academic writing. Amsterdam: John Benjamins.

Knight, P. and Yorke, M. (2004) Learning curriculum and employability in higher education. London: Routlege Falmer. 
Kotzee, B. and Johnson, R. (2008) Stringing a simple sentence together: business graduates' writing skills and employability. BMAF research and development grant final report. London: Queen Mary University of London.

Land, R., Cousin, G., Meyer, J. and Davies, P. (2005) 'Threshold concepts and troublesome knowledge (3): implications for course design and evaluation', in Rust, C. (ed.) Improving student learning, diversity and inclusion. Oxford: Oxford Centre for Staff and Learning Development, pp. 53-64.

Lave, J. (2009) 'The practice of learning', in Illeris, K. (ed.) Contemporary theories of learning. London: Routledge, pp. 200-209.

Lave, J. and Wenger, E. (2005) Situated learning: legitimate peripheral participation. Cambridge: Cambridge University Press.

Leckey, J. and McGuigan, M. (1997) 'Right tracks - wrong roads: the development of generic skills in higher education', Research in Higher Education, 38(3), pp. 365378.

Meyer, J. and Land, R. (2003) 'Threshold concepts and troublesome knowledge: linkages to ways of thinking and practising within the disciplines', Enhancing Teaching and Learning Environments, Occasional Report 4.

Morley, L. (2007) 'The X factor: employability, elitism and equity in graduate recruitment', Contemporary Social Science, 2(2), pp. 191-207.

Morley, L., Eraut, M., Aynsley, S., MacDonald, D. and Shepherd, J. (2006) Needs of employers and related organisations for information about quality and standards of higher education: a report to HEFCE by the University of Sussex School of Education. East Sussex: University of Sussex.

Wingate, U. (2006) 'Doing away with 'study skills', Teaching in Higher Education, 11(4), pp. 457-469. 
Wingate, U. (2007) 'A framework for transition: supporting 'learning to learn", Higher Education Quarterly, 61(3), pp. 391-405.

\section{Author details}

All authors were members of the UK Higher Education Academy (HEA) research project 'Literacies Supporting Learning and Enhancing Employability in a Diverse Undergraduate Population' based at the University of Central Lancashire. Corresponding author Yvon Appleby can be contacted at YAppleby@uclan.ac.uk. 